\section{Chinese Traditional Handicraft EDUCATION USING AR CONTENT}

Yi Ji, Department of Art and Design, Guangdong University of Technology, Guangzhou, 510000, China; De Montfort University, Leicester LE1 9BH, U.K. Email: jiyi001@hotmail.com.

Peng Tan, Department of Art and Design, Guangdong University of Technology, Guangzhou, 510000, China.

Damian Hills, Queensland College of Art, Griffith University, Brisbane QLD, 4101, Australia.

See www.mitpressjournals.org/toc/leon/53/2 for supplemental files associated with this issue.

Submitted: 25 June 2019

\section{Abstract}

This paper proposes a new Chinese traditional handicraft learning mode through embodied interaction using WebAR technology. It details how emergent technologies for cognitive learning can enhance learning in the teaching of a traditional handicraft. A study is presented where students learn about traditional handicrafts with a whole-body interactive simulation utilizing WebAR devices, and this is compared to traditional methods using a desktop version for the simulation. Results show that the Chinese traditional handicraft learning mode based on WebAR affords embodied interaction and improves learning between real context and virtual devices; thus WebAR devices enhance embodied interaction of traditional handicraft simulations. This contribution is highly relevant for users who aim to learn and be creative in different contexts that deliver new forms of Chinese traditional handicraft learning.

In recent years, there has been an increasing interest in applying augmented reality (AR) to create meaningful interaction in teaching domains $[1,2]$. More and more countries and regions focus on the promotion and teaching of local handicrafts, especially in China. The Chinese government enacted the relevant regulations for public participation in Chinese traditional handicraft classes. Taking the teaching of Cantonese porcelain (one of China's traditional handicrafts) as an example, 60 schools in Guangzhou, China, have offered a course teaching this craft.

The teaching of traditional handicrafts in physical and digital environments remain wide apart. The main context of the Chinese traditional handicraft teaching experience in our investigation is based on its offline class teaching mode (see Fig. 1). In this context, students always simulate the teacher's step-by-step handicraft teaching actions, which affects the efficiency of the students' learning process [3].

This paper presents a new Chinese traditional handicraft learning mode through embodied interaction based on WebAR technology. This mode integrates interaction technology (AR) with its visualization, user cognition, behavior training and content learning (the traditional handicraft itself) in context. This mode will potentially enhance Chinese traditional handicraft learning and help users experience the handicraft interactively. In addition, the discussed research project's

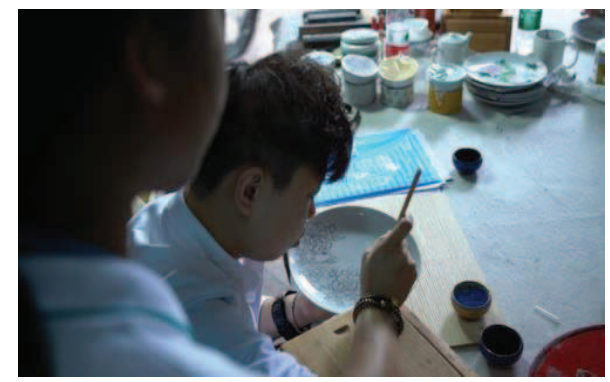

Fig. 1. Traditional craft teaching in an offline class. (C) Peng Tan) timeliness and merit are shown in a case study of learning Cantonese porcelain using WebAR. In this paper, we demonstrate that (1) WebAR devices enhance embodied interaction, therefore improving the learning experience in a traditional Chinese handicraft teaching context; and (2) the teaching of Chinese traditional handicrafts based on interactive devices should consider tangible and social interaction with artifacts rather than interaction with an abstract display in class.

\section{Embodied Interaction}

Embodied interaction is interaction with computers that occupy our world - a world of physical and social reality — and exploits how computers interact with us [4]. Tangible and radically new kinds of digital settings are emerging, including augmented materials, tools and artifacts; these are also more social in the sense that artifacts embedded in the setting are coming more and more into focus [5] in relation to the real setting of a Chinese traditional handicraft class.

\section{Embodied Learning Based on Digital Environments}

As technology develops, applications of technology like traditional Chinese handicraft teaching are becoming more immersive in environments that combine virtual and physical elements [6]. Educational researchers have already acquired some cases to test it. Yiwen et al. discuss how to use AR technology to display the features of intangible cultural heritage to solve problems such as site constraints, single display forms and overly rigid display modes in current museum displays [7]. Kim et al. present an augmented reality application for providing contextual information on cultural heritage sites; this application shows the detailed content of Injeongeon [8]. Many related papers also mention the effectiveness of AR technology in nontraditional education. A different application case has greatly improved the user cognition and learning of Chinese traditional handicrafts. However, interaction and learning with technology has increasingly divided the physical and digital worlds. Our research focuses not only on directly displaying images but on the meaningful interaction between craft and devices.

\section{Why Choose WebAR as a Tool?}

App companies that follow web standards, such as Tencent and WeChat, allow their built-in browsers to function with WebAR - this improves usability, as the user is already familiar with these apps and uses them daily. The use of QR codes (common in China) allows a user to easily download the app and bypass app stores (note that the usability of these QR codes is specific to China). WebAR can therefore reduce the limitations of devices and platforms and enhance the user experience compared to traditional interactive technology. WebAR can also use browser hyperlinks for accessing applications.

\section{Embodied Interaction for Chinese Traditional Handicraft Learning Mode Based on WebAR} We present a Chinese traditional handicraft mobile learning mode through embodied interaction (Fig. 2) to enhance learning in traditional handicraft teaching (that is, for embodied cognition in physical and digital worlds of learning) using WebAR technology. This mode integrated physical worlds (Chinese traditional craft) and digital worlds (devices) for students' learning experience in a real class. We employed 
this mode with Cantonese porcelain teaching for a case study in the local university.

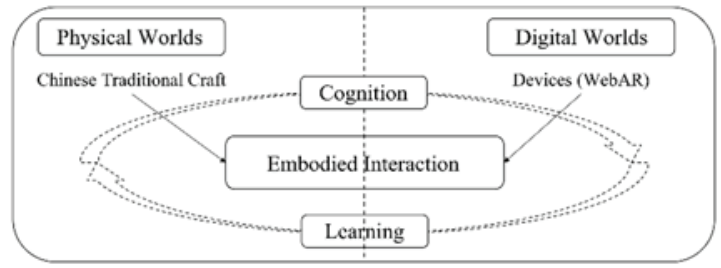

Fig. 2. Embodied interaction in traditional Chinese handicraft study based on WebAR. (C) Peng Tan)

\section{Case Study of Cantonese Porcelain}

The case discussed in this paper is a class on the traditional Chinese handicrafts of Cantonese porcelain through embodied interaction. To investigate impacts on outcomes of the teaching of WebAR as a tool for Chinese traditional handicrafts, we conducted a pilot study class in Guangdong University of Technology, Guangzhou, China. This form of embodied interaction allows the user to physically understand the gestures that a master craftsman would perform while painting a plate. In this regard, we feel that most class participants would prefer to engage with an artifact directly to increase their understanding of how the artifact was crafted, beyond traditional presentations such as videos and textbooks.

Therefore, we use circular porcelain objects (see Fig. 3), with an AR marker placed on them to, in this case, simulate a plate object. The idea is that the class participant can handle the circular object to simulate the physical affordances of the plate and experience how the plate is held during the crafting phase [9]. As a part of the presentation, a video shows how the craftsman would hold and turn a plate with his left hand while holding the brush with his right hand and painting with elegance and ease.

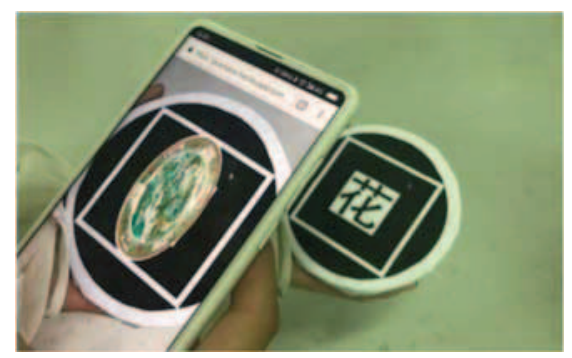

Fig. 3. A case of learning the use of Cantonese porcelain. (C) Peng Tan)

With this instruction, the participant is asked to engage with the object in a similar fashion, with the participant's mobile device as the "paintbrush" with a particular viewpoint and orientation associated with working on the finer details of the plate. This is a form of embodied interaction that mirrors how the craftsman is able to turn the plate with one hand and paint with the other hand. This type of embodied engagement increases the understanding of how the crafting process is performed while highlighting the mental focus and diligence that is required to create this kind of artifact.

\section{Detailed Case Study Setup}

The case study requires technology based on WebAR and consists of two parts.

Part one is focused on transformational knowledge of traditional Chinese handicrafts: First, we need to extract relevant materials, such as texts and pictures from the literature of the traditional handicrafts, use computer image processing technology for the 2D image data in order to improve resolution and then save the pictures as a texture in a format that is compatible with 3Dmax. Second, the original model is built in 3Dmax according to the shape of the traditional handicraft extracted from the materials. The model should adjust its coordinates, size and position according to the WebAR display standard. After the model has been built, the processed texture is mapped onto the model. Finally, the 3Dmax software is used to export the model to a format that is supported by Three.js, such as FBX.

Part two is focused on embodied interaction from cognition to learning in different contexts: network links and a marker are generated by analyzing knowledge of transformations during the development of traditional Chinese handicraft. Then the printed marker is placed in the offline display environment. Participants can then view the 3D Cantonese porcelain dynamic display through the camera on their mobile device and can also interact with the display through the device, which simulates the steps that a craftsman follows to create a painting on the object.

\section{Conclusion}

We believe embodied interaction techniques can enhance the cognitive and learning experience of creating a traditional Chinese handicraft. A timely case study demonstrates that embodied interaction allows for an enhanced understanding of artifact development through the mirroring of the gestures and viewpoints of the master craftsman. This technique can develop an appreciation of the knowledge and skill required to perform artifact construction over other methods of presentation and, we hope, spark interest in the participant to study such techniques further.

\section{Acknowledgment}

This research was supported by Guangzhou Social Science Planning Project, China, No. 2018GZMZYB17.

\section{References and Notes}

1. P. Magalhães, A. Castro and C.V. Carvalho, "Augmented Reality Applied to the Teaching/Learning Environment" (2011), paper presented at the 6th Iberian Conference on Information Systems and Technologies (Chaves, Portugal: 1518 June 2011).

2. S. Yuen, G. Yaoyuneyong and E. Johnson, "Augmented Reality: An Overview and Five Directions for AR in Education," Journal of Educational Technology Development and Exchange 4, No. 1, 119-140 (2011).

3. "Introducing Cantonese Porcelain from the Perspective of Inheritors," video of previous studies of traditional teaching in craft class: https://v.qq.com/x/page/d0759lblor9.html.

4. P. Dourish, Where the Action Is: The Foundations of Embodied Interaction (Cambridge, MA: MIT Press, 2001) pp. 572-575.

5. M. Lempert, review of J. Streeck, C. Goodwin and C. LeBaron, Embodied Interaction: Language and Body in the Material World (Cambridge, UK: Cambridge Univ. Press), in Discourse Studies 15, No. 4, 481-482 (2013).

6. R. Lindgren et al., "Enhancing Learning and Engagement through Embodied Interaction within a Mixed Reality Simulation," Computers \& Education 95 (2016) pp. 174-187.

7. W. Yiwen et al, "The Intangible Cultural Heritage Show Mode Based on AR Technology in Museums-Take the Li Nationality Non-Material Cultural Heritage as an Example," Proceedings of the 3rd IEEE International Conference on Image, Vision and Computing (Chongquing, China: 27-29 June 2018) pp. 936-940

8. H. Kim et al., "An Ontology-Based Augmented Reality Application Exploring Contextual Data of Cultural Heritage Sites," Proceedings of the 2016 12th International Conference on Signal-Image Technology and Internet-Based Systems (Naples, Italy: 28 November-1 December 2016) pp. 468-475.

9. J. Dewey, Experience and Education (Kappa Delta Pi, 1938). 